\title{
INTERRELATIONSHIPS OF VITAMIN D AND PARATHYROID HORMONE IN CALCIUM HOMEOSTASIS
}

\author{
Michael T. HaRRISON, M.D., M.R.C.P. \\ Lecturer in Medicine, University of Glasgow. \\ From the Gardiner Institute of Medicine, Western Infirmary, Glasgow.
}

IN man and most mammals the concentration of calcium in the blood and body fluids remains almost constant under normal conditions, with only slight fluctuations. For the various cellular functions which are dependent on calcium, for example neuromuscular transmission, it is the ionized fraction of calcium (approximately 50 per cent of the total serum calcium level) which is important, and it is this fraction which is so carefully maintained at a constant level in the body fluids. In order to stabilize this level, an elaborate regulating mechanism is necessary, since there are many routes of entry into and exit from the blood available to calcium. Thus, calcium is added to the blood by absorption from the intestine and by resorption from bone, and leaves via formation of new bone, and by excretion into urine, fæces, sweat and milk. Changes in other components of the body fluids, protein, citrate and phosphate, affect the concentration of ionized calcium. The magnitude of all these factors will vary in response to growth, dietary intake, changes in activity, or pregnancy, and yet the net effect on concentration of ionized calcium is almost undetectable. Two factors of major importance in the regulation of serum levels of calcium are the parathyroid glands and vitamin $\mathrm{D}$, and both of these are necessary to maintain normal levels.

\section{Parathyroid Glands}

If the parathyroid glands are removed, calcium in the serum falls rapidly to a level at which increased neuromuscular irritability occurs, with the syndrome of tetany. The parathyroid hormone raises the level of serum calcium, and a fall in this level is the principal stimulus to the secretion of hormone by the parathyroid glands. When the level of serum calcium exceeds normal, secretion of parathyroid hormone is suppressed until the level has returned to normal (McLean, 1957). These effects have been clearly demonstrated by Copp and Davidson (1961), who perfused a dog's parathyroid glands with blood of low or high calcium concentration, and showed that reciprocal changes in concentration of calcium in the systemic circulation resulted. The mechanism by which the parathyroid glands regulate their secretion in response to changing levels of serum calcium is quite unknown.

The parathyroid hormone has been purified from bovine glands, and its properties have been studied (Rasmussen and Craig $1961,1962)$. It is a protein of molecular weight approximately 9,000 , composed of a single chain containing 76 to 83 amino-acid residues. It is antigenically pure, and antibodies have been prepared to it which provide the basis for a sensitive immunoassay (Berson, Yalow, Aurbach and Potts, 1963; Tashjian, Levine and Munson, 1963). The most striking action of the hormone is that on the skeleton, which results in release of calcium into the blood. There is abundant evidence for this direct action of parathyroid hormone on bone, which has been reviewed by Munson (1960), and strengthened by the striking experiments of Gaillard (1961), who demonstrated resorption of bone in tissue culture in response to the hormone. The mechanism by which parathyroid hormone increases resorption of bone is not known. The solubility of bone depends on $\mathrm{pH}$ of the surrounding fluid; as $\mathrm{pH}$ falls solubility increases, so that bone is resorbed. A possible mechanism for the action of parathyroid hormone on bone would therefore be through a lowering of $\mathrm{pH}$ of the fluid immediately in contact with the bone. This is the basis of the "acid theory" of action of parathyroid hormone (Neuman, Firschein, Chen, Mulryan and DiStefano, 1956; Firschein, Neuman, Martin and Mulryan 1959). These workers showed that the concentration of citrate in blood obtained from the spongy bone of the dog's femur increased strikingly after injection of parathyroid hormone. They postulated that as a result of accumulation of citrate, $\mathrm{pH}$ of the fluids surrounding the bone falls, and increased resorption of bone then occurs. The citrate may also chelate some of the calcium released by bone resorption, and thus raise the 
gradient of ionic calcium between bone and the surrounding fluid. This theory has led to a large amount of research into the effect of parathyroid hormone on the production of organic acids by bone in vitro, and unfortunately there has been little agreement between different workers. Massive doses of parathyroid hormone have usually been necessary in order to produce an increase in levels of bone citrate, perhaps because of the relatively large amount of citrate present in bone in the basal state. Moreover, lactate is produced by bone in amounts approximately a hundred times greater than those of citrate in response to the hormone (Vaes and Nichols, 1961), and it is therefore possible that lactate is of greater importance than citrate in producing resorption of bone. The conflicting results of in vitro studies have been reviewed by Firschein (1963). Many workers still believe, however, that parathyroid hormone stimulates the release of citrate from bone, either by increasing its rate of formation (Ranney, 1960; Lekan, Laskin and Engel, 1960), or by inhibiting its oxidation (Neuman and Dowse, 1961; Hekkelman, 1961).

Although the skeleton is probably the most important site of action for parathyroid hormone it is not the only one. There is evidence that the hormone affects the transport of calcium in the kidney, gut and mammary gland. In the kidney, Talbot, Sobel, McArthur and Crawford (1954) first suggested that parathyroid hormone increases the reabsorption of filtered calcium by the renal tubules, so that the urinary clearance of calcium is reduced. Thus in hypoparathyroidism there may be normal or even high levels of urinary calcium in spite of hypocalcæmia, while in hyperparathyroidism, in spite of hypercalcæmia, an abnormally raised urinary excretion of calcium is not always present. Kleeman, Bernstein, Rockney, Dowling and Maxwell (1961) showed that parathyroid extract produced a significant reduction in urinary calcium clearance at all levels of diffusible calcium, both in the majority of normal and in hypoparathyroid individuals. Low clearances of calcium were noted in patients with primary hyperparathyroidism, and these rose after removal of the tumour. In carefully controlled studies on dogs, in which filtered loads of other ions were maintained constant, Widrow and Levinsky (1962) showed that urinary excretion of calcium fell after administration of parathyroid extract, although filtered calcium remained constant or increased. Similar findings have been reported in the rat by MacIntyre, Boss and Troughton (1963). It has been shown (Komarkova, Vostal an Pacovsky 1960) that parathyroid hormore produces a rise in tissue level of citrate in th kidney. There is some evidence that the level of renal citrate controls the tubular reabsor tion of calcium (Karam, Harrison, Hartog and Fraser, 1961), so that an increase in citrate level provides a possible explanation for thes effects of parathyroid hormone on urinars excretion of calcium.

Parathyroid hormone probably increases the absorption of calcium from the intestine, but less is known about the effect of the hormone on calcium absorption than about that vitamin D. Rasmussen (1959) showed that active transport of calcium by segments of raी duodenum in vitro was increased by parathyroia hormone. Balance studies in rats (Crame? Suiker and Copp, 1961) indicated a marke increase in the net absorption of calcium in response to parathyroid hormone, provides that intake of calcium was adequate. In Thirye Vella fistulas in dogs, Cramer (1963) showed. that administration of the hormone increased absorption of calcium while parathyroidectomg resulted in a decrease. In man, Jaworski, Browris. Fedoruk and Seitz (1963), using a tracer test of calcium absorption with calcium-45, 退 monstrated increased intestinal absorption ơf calcium in a patient with hyperparathyroidișpo

In lactating rats, administration of paras thyroid hormone results in a decrease of calciuri concentration in the milk, while parathyroido ectomy leads to increased secretion of calcium? suggesting that the parathyroid glands inhibi the secretion of calcium by the mammary gland (Toverud, 1963).

It can be seen that all the effects of parathyroid hormone described on calcium trans은 port lead to an increase in the amount of calcium in the blood and body fluids, so tha through several different mechanisms the para: thyroid glands effectively counter falling levels of serum calcium. From a teleological point of view, it seems most appropriate that calcium made available through resorption of bones is not all lost to the body through urinary of fæcal excretion but is retained in the bloodo The parathyroid has been justly called "glandes de protection du capital calcique" (LichtwitzN 1961).

Indirect Effects of Parathyroid Hormone off Calcium

Parathyroid hormone also affects the meta $\stackrel{\infty}{=}$ bolism of inorganic phosphorus and probablyo of magnesium, and in this way produces second $\overrightarrow{\mathrm{D}}$ ary effects on calcium. The hormone inhibits 
renal tubular reabsorption of inorganic phosphorus by a direct action on the renal tubules, resulting in an increase in urinary phosphorus and a fall of serum levels (Lavender, Pullman, Rasmussen and Aho, 1961; Horwith, Rich, Thompson and Rasmussen, 1961). The decrease in serum levels of inorganic phosphorus tends to raise the level of calcium in the serum, by preventing precipitation of calcium phosphate in bone which occurs when the solubility product for calcium and phosphate is exceeded.

MacIntyre, Boss and Troughton (1963) have shown that in the rat, parathyroid hormone also influences transport of magnesium. Both parathyroid extract and pure bovine parathyroid hormone produce a fall in excretion of magnesium in the urine, while parathyroidectomy leads to a decrease in serum levels of magnesium. These workers suggest that a fall in serum level of magnesium stimulates the parathyroid glands, and the increased secretion of hormone is the cause of the hypercalcæmia which occurs in magnesium-deficient rats. Changes in concentration of magnesium may therefore upset the normal homøostatic control of calcium.

\section{Calcitonin}

Evidence has recently been presented in favour of the existence of a second parathyroid hormone, the action of which is opposite to that of the serum calcium-raising hormone. This second hormone, named calcitonin, was postulated as a result of perfusion experiments on the dog's thyroid and parathyroid glands with hypercalcæmic blood (Copp, Cameron, Cheney, Davidson and Henze, 1962). This caused an immediate transitory hypocalcæmic effect on systemic blood, which occurred significantly earlier than did hypocalcæmia observed after total parathyroidectomy, indicating that suppression of secretion of parathyroid hormone could not account for the rapid effect. No hypocalcæmic effects were observed when only the thyroid gland was perfused with hypercalcæmic blood. A similar hypocalcæmic action was demonstrated for parathyroid extract and for purified bovine parathyroid hormone (Copp and Cameron, 1961). Copp concluded that the parathyroid glands secrete calcitonin in response to hypercalcæmia and in this way restore the level of calcium to normal. Such a mechanism would provide a more rapid regulation than the simpler feedback mechanism depending on only one hormone.

The existence of a calcium-lowering factor secreted by the parathyroid in response to hypercalcæmia in the dog has been confirmed by Kumar, Foster and MacIntyre (1963). In other animals, however, attempts to demonstrate calcitonin have not so far been successful (Tashjian and Munson, 1963). In man, the possibility that a calcium-lowering hormone exists has been suggested by the finding of unexplained hypocalcæmia in a patient with hyperplasia of the parathyroid glands (Frame, Fruchtman and Smith, 1962), and of wide fluctuations of serum levels of calcium in another patient with a parathyroid tumour (Haas, Affolter and Dubach, 1964). The latter group have also found a transient decrease in levels of serum calcium following injection of parathyroid extract in one patient, suggesting a calcitonin effect.

The theory of a dual regulation of calcium homeostasis by two parathyroid hormones is an attractive one, which may be compared to the regulation of blood sugar levels by insulin and glucagon. While the evidence for calcitonin is suggestive, the existence of this hormone cannot yet be regarded as proved. It will be interesting to see whether isolation and purification of a hypocalcæmic factor from the parathyroid glands can be achieved.

\section{Vitamin D}

Vitamin $\mathrm{D}$ is the other most important regulator of calcium homøostasis. Its action resembles that of parathyroid hormone in many ways, although there may be some quantitative differences in their actions. In the vitamin D-deficient rat or man, the vitamin increases the resorption of bone, even in doses which are too small to affect absorption of calcium from the intestine (Carlsson and Lindquist, 1954; Nordin, 1960). It is possible, however, that this may not be a direct action of the vitamin, but mediated through the parathyroid glands, as will be discussed. Experiments with bone in vitro also demonstrate an increased resorption in the presence of vitamin $D$, but the doses used are larger. Nichols, Schartum and Vaes (1963) incubated mouse bones in a buffer and measured the concentrations of calcium, phosphorus, and lactate in the buffer at equilibrium. Bones from animals treated with vitamin D equilibrated with higher concentrations of calcium and phosphorus than did bones from vitamin D-deficient animals, suggesting that vitamin $\mathrm{D}$ alters the bone-blood equilibrium to a higher level. Levels of lactate were also higher in the case of the animals receiving vitamin $D$, and it will be recalled that parathyroid hormone produces the same effect. There is some evidence 
that vitamin D leads to an increase in citrate levels in bone, but as in the case of parathyroid hormone this is uncertain. Vitamin D also mobilizes calcium-45 in vivo from labelled bones of rats (Clark, 1961).

The action of vitamin D on the intestine has been thoroughly studied. There is abundant evidence that the vitamin facilitates the absorption of calcium, both in animals and in man. In the rat, the principal site of action of vitamin $\mathrm{D}$ is the upper jejunum (Schachter, Kimberg, and Schenker, 1961), and at least in this species its action is a direct one, without prior activation of the vitamin elsewhere in the body (Schachter, Kowarski and Finkelstein, 1964). Such an activation had been suggested previously because of the delay in onset of the effects of vitamin D after administration. Vitamin D may enhance intestinal absorption of calcium by stimulating an energy-dependent active transport mechanism (Schachter, 1963), by altering cellular permeability to calcium (Harrison and Harrison, 1960), or by increasing the cellular content of citrate, and thereby raising the gradient of citrate between gut and blood, so that citrate-bound calcium could be transported into the blood (Hanna, Alcock, Lazarus and Mullan, 1963). The recent discovery of the action of vitamin D on release of calcium bound by mitochondria (see below) may be relevant to the mechanism of intestinal absorption (Wasserman and Taylor, 1963); it is possible that vitamin $\mathrm{D}$ increases the solubility of calcium inside the intestinal cells.

The effect of vitamin $\mathrm{D}$ on renal disposition of calcium is uncertain, partly because studies of the effects of the vitamin in intact animals are complicated by changes in parathyroid gland function. It appears that vitamin $D$ does not increase the tubular reabsorption of calcium in the way that parathyroid hormone does (Kleeman and colleagues, 1961). In patients with hypoparathyroidism vitamin D may produce a striking increase in urinary excretion of calcium, although levels of serum calcium remain low (Litvak, Moldawer, Forbes and Henneman, 1958). This may indicate either that vitamin D decreases the tubular reabsorption of calcium, as these workers suggested, or that tubular reabsorption is unaffected and the increased urinary calcium results from a greater filtered load. In a single experiment on a dog, however, Gran (1960a) observed that vitamin D raised serum levels of calcium and at the same time urinary excretion of calcium decreased.
From these observations it cannot bo definitely stated whether vitamin D affects the renal transport of calcium or not, but if any. effects are produced they are slight compared to those produced by parathyroid hormone.

\section{The Role of Citrate}

Both vitamin D and parathyroid hormon produce an increase in levels of citrate in the blood and in most tissues of the body (Harrisot and Harrison, 1952; Steenbock and Bellin 1953; Carlsson and Hollunger, 1954; Hanna and others, 1963). It is therefore possible that both substances produce their effects on calciugo metabolism by the same metabolic process, which citrate is in some way involved. The possible roles of citrate in resorption of bone? in intestinal absorption of calcium, and i i⿱ urinary excretion of calcium have already bee? mentioned. The mechanism of the increase if citrate production is unknown. It has been shown, however, that vitamin $\mathrm{D}$ reduces the rate of oxidation of citrate in kidnex mitochondria (DeLuca, Gran, Steenbock and Reiser, 1957). Harrison and Harrison (19639 suggest that the effects of vitamin D on citrate metabolism are secondary and incidentalotg those on calcium metabolism, since simifar increases in concentration of citrate result frạm administration of calcium by either intravenous or intraduodenal routes. Moreover cortis $\Phi$ inhibits the increase in citrate levels produce by vitamin $\mathrm{D}$ but does not affect its calcium? mobilizing effects (Harrison, Harrison an $\vec{\Phi}$ Park, 1957). The significance of changes in metabolism of citrate in relation to calcium homøostasis is therefore uncertain, but it is possible that the calcium-mobilizing effects of parathyroid hormone and vitamin $\mathrm{D}$ are primary ones which lead to secondary effects o巴 citrate, rather than the reverse.

\section{Binding of Calcium by Mitochondria}

It has been shown recently that vitamin and parathyroid hormone influence the rate og release of calcium by mitochondria (DeLuca) Engstrom and Rasmussen, 1962; Engstrom an ${ }^{\mathbb{P}}$ DeLuca, 1962). In rat mitochondria, calciuns is bound in the presence of a system whictu generates adenosine triphosphate. Whe vitamin D or parathyroid hormone is added t@ the system the bound calcium is released.

Parathyroid hormone, however, does no produce this effect on mitochondria from vitamin D-deficient animals, unless vitamin D? is added to the system also. The hormone in addition stimulates the uptake of phosphoris 
by the mitochondria, and this effect is observed even in the absence of vitamin D (Sallis, DeLuca and Rasmussen, 1963). Possibly the primary action of parathyroid hormone is to facilitate mitochondrial uptake of phosphorus, and vitamin D serves to couple this to the calcium-releasing effect. Although the mechanism of binding of calcium by the mitochondria is unknown, it seems likely that it is linked to phosphorus generated by adenosine triphosphate. Since parathyroid hormone also uncouples oxidative phosphorylation in the mitochondria (Fang, Rasmussen, DeLuca and Young, 1963), it may inhibit generation of phosphorus compounds which can combine with calcium, and thereby lead to release of calcium.

These new discoveries are of great interest, and provide a possible explanation for some of the observed effects of parathyroid hormone and vitamin $D$, in particular the dependence of the calcium-mobilizing effect of parathyroid hormone, to be discussed in the next section.

\section{Relationship between Parathyroid Hormone and Vitamin $D$}

It is clear that parathyroid hormone and vitamin $\mathrm{D}$ have many metabolic effects in common, and for years a close relationship between them has been suspected. It seems basically unlikely that two substances so different in chemical structure, one a polypeptide and the other sterol-like, should both affect calcium metabolism completely independently of one another, and yet in so similar a manner. It was first suggested that vitamin D might act by stimulating the parathyroid glands (Shelling, 1935). This was soon shown to be incorrect, however, since vitamin $\mathrm{D}$ can maintain normal levels of serum calcium after removal of the parathyroid glands, and in other forms of hypoparathyroidism. The vitamin also produces its usual effect on intestinal absorption of calcium in parathyroidectomized rats (Gran, 1960b). Nevertheless, evidence for a functional relationship between vitamin $\mathrm{D}$ and parathyroid hormone has continued to accumulate, and the earlier work has been reviewed by Neuman and Neuman (1958). More recent experiments have shown that parathyroid hormone fails to raise the serum levels of calcium in rats with vitamin D deficiency, whose serum levels of calcium are low and of phosphorous high (Crawford, Gribetz, Diner, Hurst and Castleman, 1957; Harrison, Harrison and Park, 1958; Marnay and Raoul, 1959). If the animals are first treated with vitamin D, however, administration of parathyroid hormone then produces its expected effects on calcium mobilization and the serum levels rise. Rasmussen, DeLuca, Arnaud, Hawker and von Stedingk (1963) have confirmed that parathyroid hormone fails to correct the hypocalcæmia of severely vitamin D-deficient rats, although when given in a massive dose of 2,000 units a rise in serum level of calcium did occur. This very large dose, however, influenced calcium mobilization to a much smaller degree than in rats receiving vitamin $\mathrm{D}$, in which hypercalcæmia and nephrocalcinosis rapidly occurred. After the vitamindeficient rats had received vitamin $D$, a dose of parathyroid hormone as small as 25 units was sufficient to raise serum levels of calcium, while a dose of vitamin $D$ of only 0.3 unit restored sensitivity to parathyroid hormone. Rasmussen and colleagues also showed that the parathyroid glands of the vitamindeficient animals were far from inactive, since their removal resulted in a striking increase in serum levels of phosphorus. Evidently, the phosphaturic action of parathyroid hormone is unimpaired in these animals, and only the calcium-mobilizing activity is affected. It has repeatedly been observed, moreover, that the parathyroid glands are enlarged in vitamin Ddeficient animals, suggesting increased activity (Crawford and colleagues, 1957; Harrison and Fraser, 1960a, 1960b). It is of great interest that the dissociation of phosphorus-and calcium-mobilizing effects of parathyroid hormone in vitamin D-deficient rats is exactly what would be predicted from the observations on mitochondrial transport of calcium and phosphorus already described; in the absence of vitamin $\mathrm{D}$, parathyroid hormone apparently influences phosphorus transport normally, but is without effect on mobilization of calcium, except in massive doses.

In vitamin D-deficient mice, a similar failure of parathyroid hormone to affect serum levels of calcium could not be demonstrated (Nichols and colleagues, 1963) but it has been suggested that the degree of vitamin deficiency may not have been severe enough to abolish sensitivity to parathyroid hormone (Rasmussen and colleagues, 1963).

In man, the effects of vitamin $\mathrm{D}$ deficiency differ from those observed in the rat, in that serum levels of phosphorus are generally lower, while the levels of calcium may be normal or only slightly reduced. There is a considerable amount of evidence that vitamin $D$ deficiency leads to secondary overactivity of the parathyroid glands, which tends to correct the hypocalcæmia by mobilization of calcium from 
the skeleton, and at the same time reduces the serum levels of phosphorus by increasing urinary excretion. Evidence suggesting a state of hyperparathyroidism is provided by (a) the finding of increased calcium deposition in and resorption from bone in osteomalacia (Fraser, Harrison and Ibbertson, 1960; Nordin, Smith and Nisbet, 1964); (b) X-ray examination of the skeleton, which in vitamin $\mathrm{D}$ deficiency may show subperiosteal erosions and cysts typical of hyperparathyroidism (Davies, Dent and Willcox, 1956); (c) the urinary excretion of phosphorus, which is normally raised as in hyperparathyroidism (Nordin and Fraser, 1960). This increased excretion is suppressed by an infusion of calcium (Nordin and Fraser, 1954), provided that the serum levels of calcium are raised above normal by the infusion and so suppress secretion of parathyroid hormone; (d) the parathyroid glands themselves, which are enlarged and in rare instances may develop adenomas (Fourman, 1960; Davies and colleagues, 1956).

The response of the parathyroid glands to vitamin $\mathrm{D}$ deficiency tends to return the serum calcium levels to normal at the expense of skeletal calcium, and so tetany is prevented. In some patients with vitamin D deficiency, however, this secondary hyperparathyroidism is inadequate or may even fail to occur, so that the serum levels of calcium fall, resulting in tetany. Bernstein, Kleeman, Dowling and Maxwell (1962) described a patient with steatorrhœa and tetany, in whom administration of parathyroid hormone failed to raise the serum level of calcium, although increased urinary excretion of phosphorus did occur. A bone biopsy revealed no evidence of osteomalacia or of osteitis fibrosa. Only after partial treatment with vitamin D did parathyroid hormone produce the expected rise in serum levels of calcium. It appeared that in this patient there was unresponsiveness to the calciummobilizing effect of parathyroid hormone while vitamin $\mathrm{D}$ deficiency persisted, and that normal responsiveness to the hormone was restored by therapy with vitamin $D$. This phenomenon is similar to that observed in the vitamin $D$ deficient rats. In children with rickets due to vitamin $\mathrm{D}$ deficiency, failure of parathyroid hormone to raise serum levels of calcium has also been noted (Jonxis, 1961; Steendijk, 1964).

In vitamin D-deficient rats and in humans whose serum levels of calcium fail to respond to parathyroid hormone, an alternative possibility to parathyroid hormone unresponsive- ness must be considered. When osteomalacio is present, as would be expected in chronic vitamin $\mathrm{D}$ deficiency, the bones are abnormally avid for calcium, as shown by calcium infusion (Nordin and Fraser, 1954), or by tracer tests with strontium (Fraser and colleagueg, 1960). Parathyroid hormone administered animals or humans with osteomalacia mighe in fact, mobilize calcium from the skeleton the usual way, but the liberated calcium woukd not raise serum levels appreciably because it would be immediately taken up by the avid osteomalacic bone. Even normal bone may rapidly take up some of the calcium released by parathyroid hormone (Johnston, Mines Smith and Deiss, 1962), and so partially maste the hypercalcæmic effect of the hormone. This absence of osteomalacia in a bone biopsiy taken from Bernstein's patient does not favoup this possibility, but osteomalacia, in the same way as other metabolic diseases of bone, may be patchy and not generalized, so that it cant not be definitely excluded from a single biops $\overrightarrow{y_{5}}$

Thus in humans with vitamin $\mathrm{D}$ deficienc increased parathyroid activity is generall apparent, but on rare occasions a refractory state to the calcium-mobilizing action of pक्ष thyroid hormone may occur, although the explanation for this may be questioned. P ibly it is only in the most severe states of vitamin $D$ deficiency that the calciums mobilizing action of parathyroid hormone fails and only rarely is the deficiency severe enough to produce complete unresponsiveness. In the rat, very small amounts of the vitamin are ade quate to restore responsiveness to parathyroid hormone (Rasmussen and colleagues, 1963

In view of these observations, it seems that the action of small doses of vitamin D on the skeleton, demonstrated by Carlsson and Linds quist (1955) and Nordin (1960) may not be. direct, but mediated through the parathyroi $\$$ glands, which failed to mobilize calcium from the skeleton in adequate amounts until the vitamin was administered. There is no doubs however, that large doses of vitamin $\mathrm{D}$, a used in the treatment of hypoparathyroidism stimulate resorption of calcium from the skeleton by a direct action.

Neuman and Dowse (1961) suggested that vitamin $\mathrm{D}$ might be the fundamental calciume regulating factor, and that parathyroid hormone modified its actions. They pointed out tha parathyroid hormone appeared later than vita? min $D$ in the process of evolution and that parathyroid glands are absent in the teleos? fishes, which store large amounts of vitamip $D$ in the liver. Possibly, abandoning the 
calcium-rich marine environment for a life on dry land necessitated a more efficiently regulated system for calcium homœostasis, and the parathyroid glands evolved accordingly. A basic action of vitamin D, which affected transfer of energy in the mitochondria through DPN or TPN, was postulated: parathyroid hormone might then increase the activity of vitamin $\mathrm{D}$ and render its action more specific.

At the time this hypothesis was put forward there was little evidence to support it. It must have been gratifying to these workers, and of interest to all workers in the field of calcium metabolism, when the striking effects of vitamin D and parathyroid hormone on mitochondria were discovered. It now seems probable that vitamin $\mathrm{D}$ is indeed required for full expression of the effects of parathyroid hormone, and that these effects are produced at the mitochondrial level, probably by influencing oxidative phosphorylation. The importance of these now findings in regard to calcium homœostasis cannot yet be assessed. They provide a possible explanation for the failure to demonstrate the calcium-mobilizing effect of parathyroid hormone in states of vitamin D deficiency, although as pointed out, further proof that the unresponsiveness is real is still required.

\section{Conclusion}

The relationship between parathyroid hormone and vitamin D, suspected for many years, has been confirmed by exciting new discoveries of effects on mitochondrial transport of calcium and phosphorus. These findings help to explain some of the metabolic effects of parathyroid hormone and vitamin $\mathrm{D}$, and also the diffculties in proving whether differences between their actions exist. Since one of the primary effects of parathyroid hormone appears to be stimulation of uptake of phosphorus by mitochondria, it is appropriate to end with a prophetic remark by Albright, in 1948: "Parathyroid hormone may act primarily on phosphorus metabolism in some way which not only increases the excretion of phosphorus in the urine but. also produces certain bone changes directly." The accuracy of this prediction is now beginning to be apparent.

The author is grateful to Dr. D. A. Smith for helpful suggestions.

\section{REFERENCES}

Albright, F., and Reifenstein, E. C., Jr. (1948): 'The Parathyroid Glands and Metabolic Bone Disease', p. 23, Baltimore: Williams and Wilkins.

Bernstein, D., Kleeman, C. R., Dowling, J. T., and Maxwell, M. H. (1962): Steatorrhœa, Functional Hypoparathyroidism, and Metabolic Bone Defect, Arch. intern. Med., 109, 43.

Berson, S. A., Yalow, R. S., Aurbach, G. D., and PotTS, J. T., Jr. (1963): Immuno-assay of Bovine and Human Parathyroid Hormone, Proc. nat. Acad. Sci. (Wash.), 49, 613.

CARLSSON, A., and LINDQUIST, B. (1955): Comparison of Intestinal and Skeletal Effects of Vitamin D in Relation to Dosage, Acta physiol. Scand., 35, 54.

Carlsson, A., and Hollunger, G. (1954): The Effect of Vitamin D on the Citric Acid Metabolism, Ibid, 31, 317.

CLARK, L. (1961): Agents Effecting the Removal of Skeletal Radiocalcium and Radiophosphorus from Intact and Parathyroidectomized Rats. In 'The Parathyroids' p. 183. Springfield, Illinois: Charles C. Thomas.

COPP, D. H., and CAMERON, E. C. (1961): Demonstration of a Hypocalcemic Factor i(Calcitonin) in Commercial Parathyroid Extract, Science, 134, 2038.

Copp, D. H., and DAvidson, A. G. F. (1961): Direct Humoral Control of Parathyroid Function in the Dog, Proc. Soc. exp. Biol. Med., 107, 342.

Copp, D. H., Cameron, E. C., Cheney, B. A., Davidson, A. G. F., and Henze, K. G. (1962): Evidence for Calcitonin-a New Hormone from the Parathyroid that Lowers Blood Calcium, Endocrinology, 70, 638.

Cramer, C. F., SuIKer, A. P., and CoPP, D. H. (1961): Parathyroid Influence on Calcium and Phosphorus Absorbtion by the Gut. In 'The Parathyroids', p. 158. Springfield, Illinois: Charles C. Thomas.

CRAMER, C. F. (1963): Quantitative Studies on the Absorption and Excretion of Calcium from Thiry-Vella Intestinal Loops in the Dog. In 'The Transfer of Calcium and Strontium across Biological Membranes', p. 75, New York: Academic Press.

Crawford, J. D., Gribetz, D., Diner, W. C., Hurst, P., and Castleman, B. (1957): The Influence of Vitamin $D$ on Parathyroid Activity and the Metabolism of Calcium and Citrate during Calcium Deprivation, Endocrinology, 61, 59.

Davies, D. R., DeNT, C. E., and Willcox, A. (1956): Hyperparathyroidism and Steatorrhœa, Brit. med. J., ii, 1133 .

De Luca, H. F., Gran, F. C., Steenbeck, H., and Reiser, S. (1957): Vitamin D and Citrate Oxidation by Kidney Mitochondria, J. biol. Chem., 228, 469.

De Luca, H. F., Engstrom, G. W., and RASmussen, H. (1962): Action of Vitamin D and Parathyroid Hormone in vitro on Calcium Uptake and Release by Kidney Mitochondria, Proc. nat. Acad. Sci. (Wash.), 48, 1604 .

Engstrom, G. W., and De LuCA, H. F. (1962): The Action of Vitamin D in vivo and in vitro on the Release of Calcium from Kidney Mitochondria, J. biol. Chem., 237, 974. 
Fang, M., Rasmussen, H., De Luca, H. F., and Young, R. (1963): The Influence of Parathyroid Hormoße upon Glutamate Oxidation in Isolated Mitochondria, Biochem. Biophys. Res. Commun., 10, 260.

Firschein, H. E., Neuman, W. F., Martin, G. R., and Mulryan, B. J. (1959): Studies on the Mechanisin of Action of the Parathyroid Hormone, Recent Progr. Hormone Res., 15, 427.

Firschein, H. E. (1963): Parathyroid Hormone and Vitamin D, J. chron. Dis., 16, 283.

Fourman, P. (1960): 'Calcium Metabolism and the Bone', p. 132. Oxford: Blackwell.

Frame, B., Fruchtman, M., and Smith, R. W., Jr. (1962): Chronic Hypocalcemia in a Patient wift Parathyroid Clear-Cell Hyperplasia, New Engl. J. Med., 267, 1112.

Fraser, R., Harrison, M. T., and IbBertson, H. K. (1960): The Rate of Calcium Turnover in Bone Measurement by a Tracer Test using Stable Strontium, Quart. J. Med. N.S., $29,85$.

Gaillard, P. J. (1961): Parathyroid and Bone Tissue Culture, In 'The Parathyroids', p. 20. Springfielg, Illinois: Charles C. Thomas.

Gran, F. C. 1(1960a): The Relation of Parenterally Injected Calcium in Rachitic Dogs, Acta physiol. Scand? 50, 132.

Gran, F. C. (1960b): Vitamin D and Calcium Absorption in Parathyroidectomized Rats, 1bid, 49, 211.

HaAs, H. G., AfFolter, H., and DubaCh, U. C. (1964): Evidence for a Calcitonin Effect in Man and $\vec{a}$ Syndrome of Primary Hyperparathyroidism with Possible Secondary Hypercalcitonism, Second Europeas Symposium on Calcified Tissues, Liège.

Hanna, S., Alcock, N., Lazarus, B., and Mullan, B. (1963): Changes in Gut and Urinary Citrates Followiris a Low Calcium and Magnesium Diet and Administration of Vitamin D2, J. Lab. clin. Med., 61, 220.

Harrison, H. C., Harrison, H. E., and Park, E. A. (1957): Vitamin D and Citrate Metabolism. Inhibitio of Vitamin D Effect by Cortisol, Proc. Soc. exp. Biol. Med., 96, 768.

Harrison, H. C., Harrison, H. E., and Park, E. A. (1958): Vitamin D and Citrate Metabolism; Effect Vitamin $D$ in Rats fed Diets Adequate in both Calcium and Phosphorus, Amer. J. Physiol., $192,432$.

HARrison, H. E., and HARrison, H. C. (1952): Vitamin D and Citrate Metabolism; Studies on Rachitic Infantis Yale J. Biol. Med., 24, 273.

Harrison, H. E., and Harrison, H. C. (1960): Transfer of ${ }^{45} \mathrm{Ca}$ across Intestinal Wall in vitro in Relatio 0 to Action of Vitamin D and Contisol, Amer. J. Physiol., 199, 265.

Harrison, H. E., and Harrison, H. C. (1963): Theories of Vitamin D Action. In 'The Transfer of Calcium and Strontium across Biological Membranes, p. 229, New York: Academic Press. HARrison, M. T., and Fraser, R. (1960a): Bone Structure and Metabolism in Calcium-Deficient Rats, 苛
Endocr., 21, 197. Harrison, M. T. and Fraser, R. (1960b): The Parathyroid Glands and Calcium Deficiency in the Bata
Ibid 21, 207. HekkelmaN, J. W. (1961): The Effect of Parathyroid Extract on the Isocitric Dehydrogenase Activity. ${ }^{\circ}$.
Bone Tissue, Biochim. biophys. Acta (Amst.), 47, 426.

Horwith, M., Rich, C., Thompson, D. D., and Rasmussen, H. (1961): Renal Effects of Purified Bovine Parathyroid Extract. In 'The Parathyroids', p. 415. Springfield, Illinois: Charles C. Thomas.

Jaworski, Z. F., Brown, E. M., Fedoruk, M. A., and Seitz, H. (1963): A Method for the Study of Calcium Absorption Using a Standard Dose of Calcium Labelled with Calcium 47, New Engl. J. Med5 269, 1103.

Johnston, C. C., Miner, E. B., Smith, D. M., and Deiss, W. P. (1962): Influenoe of Parathyroid Activit on the Chemical Equilibrium of Bone Calcium in vitro, J. Lab. clin. Med., 60, 689.

JonxIS, J. H. P. (1961): Some Investigations on Rickets, J. Pediat. 59, 607.

Karam, J., Harrison, M. T., Hartog, M., and Fraser, R. (1961): Renal Citrate and Urinary Calcium Excrę tion-the Effects of Growth Hormone Contrasted with those of Sodium Fluoroacetate, Clin. Sci., 21, 263.

Kleeman, C. R., Bernstein, D., Rockney; R., Dowling, J .T., and MaXwell, M. H. (1961): Studies of the Renal Clearance of Diffusible Calcium and the Role of the Parathyroid Glands in its Regulation In 'The Parathyroids', p. 353. Springfield, Illinois: Charles C. Thomas.

Komarkova, A., Vostal, J., and Pecovsky, V. (1960): Effect of Parathyroid Extract on Citric Acid Concen tration in the Rat Kidney, Nature, 185, 173

Kumar, M. A., Foster, G. V., and MacINTYRe, I. (1963): Further Evidence for Calcitonin, a Rapid-Acting Hormone which Lowers Plasma Calcium, Lancet, ii, 480.

Lavender, A. R., Pullman, T. N., Rasmussen, H., and AHo, I. (1961): Studies on the Intrarenal Effects of Parathyroid Hormone. In 'The Parathyroids', p. 406. Springfield, Illinois: Charles C. Thomas.

LeKaN, E. C., LASKIN, D. M., and ENGEL, M. B. (1960): Effect of Parathyroid Extract on Citrate Metato olism in Bone, Amer. J. Physiol., 199, 856.

Litvak, J., Moldower, M. P., Forbes, A. P., and Henneman, P. H. (1958): Hypocalcemic Hypercalciurizg during Vitamin D and Dihydrotachysterol Therapy of Hypoparathyroidism, J. clin. Endocr., 18, 246.

MacIntyre, I., Boss, S., and Troughton, V. A. (1963): Parathyroid Hormone and Magnesium Homois stasis, Nature, (Lond.), 198, 1058.

McLean, F. C. (1957): The Parathyroid Hormone and Bone, Clin. Orthop., 9, 46.

MARNEY, C., and Raoul, Y. (1959): Rôle Indispensable de la Vitamine D pour Observer l'Action Hypercalcé miante de l'Hormone Parathyroidienne chez le Rat Normal, C.R. Soc. Biol. (Paris), $153,1949$.

MunSON, P. (1960): Recent Advances in Parathyroid Hormone Research, Fed. Proc., 19, 593.

Neuman, W. F., Firschein, H., Chen, P. S., Mulryan, B. J., and DiStefano, V. (1956): On the Mechanisfin of Action of Parathormone, J. Amer. chem. Soc., 78, 3863. Neuman, W. F., Neuman, M. W. (1958): 'The Chemical Dynamics of Bone Mineral'. Chicago: Universitg
of Chicago Press.

Neuman, W. F., and Dowse, C. M. (1961): Possible Fundamental Action of Parathyroid Hormone in Bon@ In 'The Parathyroids' p. 310. Springfield, Illinois: Charles C. Thomas. 
Nichols, G. Jr., Schartum, S., and Vaes, G. M. (1963): Some Effects of Vitamin D and Parathyroid Hormone on the Calcium and Phosphorus Metabolism of Bone in vitro, Acta Physiol. Scand., 57, 51.

Nordin, B. E. C., and FrASER, R. (1954): The Effect of Intravenous Calcium on Phosphate Excretion, Clin. Sci., 31, 477.

NoRDIN, B. E. C., (1960): Hyperparathyroidism, Osteomalacia, and Osteoporosis. In 'Clinical Endocrinology'. New York and London: Grune and Stratton.

Nordin, B. E. C., and FraSer, R. (1960): Assessment of Urinary Phosphate Excretion, Lancet, i, 947.

Nordin, B. E. C., Smith, D. A., and NiSbet, J. (1964): Bone Mineralisation and Destruction. Rates Determined by Continuous Feeding of Radiocalcium, Clin. Sci., in press.

RANNEY, R. E. (1960): The Effect of Estrone and Parathyroid Extract on Bone Citrate Metabolism, Endocrinology, 67, 166.

RASMUSSEN, H. (1959): The Influence of Parathyroid Function upon the Transport of Calcium in Isolated Sacs of Rat Small Intestine, Ibid, 65, 517.

RASMUSSEN, H., and CRAIG, L. C. (1961): Isolation and Characterization of Bovine Parathyroid Hormone, J. biol. Chem., 236, 759.

Rasmussen, H., and Craig, L. C. (1962): Purification of Bovine Parathyroid Hormone by Gel Filtration, Biochim. biophys. Acta (Amst.), 56, 332.

Rasmussen, H., De LuCA, H., ARNaud, C., Hawker, C., and von Stedingk, M. (1963): The Relationship between Vitamin D and Parathyroid Hormone, J. clin. Invest., 42, 1940.

Sallis, J. D., DE LuCA, H. F., and RASMUSSEN, H. (1963): Parathyroid Hormone Stimulation of Phosphate Uptake by Rat Liver Mitochondria, Biochem. Biophys. Res. Commun, 10, 266.

SCHACHTER, D., KIMBERG, D. V., and SCHENKER, H. (1961): Active Transport of Calcium by Intestine: Action and Bio-Assay of Vitamin D, Amer. J. Physiol., 200, 1263.

SCHACHTER, D. (1963): Vitamin D' and the Active Transport of Calcium by the Small Intestine. In 'The Transfer of Calcium and Strontium across Biological Membranes', p. 197, New York: Academic Press.

Shelling, D. H. (1935): 'The Parathyroids in Health and Disease'. St Louis, Missouri : C. V. Mosby.

STEINBECK, H. and Bellin, S. A. (1953): Vitamin D and Tissue Citrate, J. biol. Chem., 205, 985.

STEENDIJK, R. (1964): The Effect of Parathyroid Extract on the Serum Concentrations of Calcium and Inorganic Phosphate in Active and Healing Rickets, Acta. Paediat. (Uppsala), 53, 105.

TAlbot, N. B., SObel, E. H., MCARTHUR, J. W., and CraWford, J. D. (1954): In 'Functional Endocrinology from Birth through Adolescence', p. 72, Cambridge, Mass. Harvard University Press.

TAshian, A. H., Jr., Levine, L., and Munson, P. L. (1963): Case Records of the Massachusetts General Hospital, New Engl. J. Med., 269, 801.

TAShian, A. H., Jr., and MunSon, P. L. (1963): Chemical Nature of Parathyroid Hormones, J. chron. Dis., 16, 269.

TOVERUD, S. U. (1963): Calcium-Vitamin D-Parathyroid Interrelationships in Lactating Rats. In 'The Transfer of Calcium and Strontium across Biological Membranes', p. 341, New York: Academic Press.

Vaes, G. and Nichols, G., Jr. (1961): Metabolic Studies of Bone in vitro III. Citric Acid Metabolism and Bone Mineral Solubility. Effects of Parathyroid Hormone and Estradiol, J. biol. Chem., 236, 3323.

WASSERman, R. H., and TAYLOR, A. N. (1963): Vitamin D-3 Inhibition of Radiocalcium Binding by Chick Intestinal Homogenates, Nature, (Lond.), 198, 30.

Widrow, S. H., and LeVINSKy, N. G. (1962): The Effect of Parathyroid Extract on Renal Tubular Calcium Reabsorption in the Dog, J. clin. Invest., 14, 2151. 